\title{
CARDIOPULMONARY PARASITIC NEMATODES OF THE RED FOX (VULPES VULPES) IN SERBIA
}

\author{
Pavle GaVRILOVIĆ ${ }^{*}$, Ivan DoBrosaVlJEVIĆ ${ }^{2}$, Nikola VASKOVIĆ ${ }^{3}$, Igor TODOROVIĆ ${ }^{4}$, \\ Aleksandar ŽIVULJ ${ }^{5}$, Branislav KURELJUŠI $\dot{C}^{6}$ and Ivan PAVLOVIĆ ${ }^{7}$ \\ ${ }^{1}$ Department of Pathology and Parasitology, ${ }^{4}$ Department of Animal Health and \\ ${ }^{5}$ Department of Epizootiology, Veterinary Specialized Institute 'Pančevo', \\ Novoseljanski put 33, 26000 Pančevo, Serbia; ${ }^{2}$ Department of Pathology, Veterinary \\ Specialized Institute 'Požarevac', Požarevac, Serbia; ${ }^{3}$ Department of Epizootiology, \\ Veterinary Specialized Institute 'Kraljevo', Kraljevo, Serbia; ${ }^{6}$ Department of Pathology \\ and ${ }^{7}$ Department of Parasitology, Scientific Veterinary Institute of Serbia, Belgrade, \\ Serbia
}

(Received 18 June 2018; accepted 20 November 2018)

\begin{abstract}
Among the wild canids, the red fox (Vulpes vulpes) is recognised as an important reservoir species for a range of parasites, including cardiopulmonary nematodes of public health and veterinary importance. As cross-host transmission between the red fox and domestic carnivores can play an important role in the epizootiology of cardiopulmonary parasitic diseases, the aim of the present investigations was to obtain data on the geographical distribution of cardiopulmonary nematodes of the red fox. The material for examination consisted of 83 foxes which were legally hunted at different locations during a three-month period from December 2017 to February 2018. The presence of four emerging species in Europe (Angiostrongylus vasorum, Crenosoma vulpis, Dirofilaria immitis and Eucoleus aerophilus) was revealed in red foxes of Serbia. Crenosoma vulpis and E. aerophilus were detected in foxes in both the plain and the mountainous areas across the country. Dirofilaria immitis is distributed in red foxes near alluvial rivers in Vojvodina province (northern Serbia). Angiostrongylosis caused by A. vasorum was demonstrated to exist in two enzootic foci with a high percentage of infected foxes in a plain area of northern Serbia. To the best of our knowledge, $C$. vulpis and A. vasorum were discovered for the first time in red foxes in central Serbia. The results provide strong evidence for veterinarians to take into consideration the parasitic nematodes discovered in red foxes in the differential diagnosis of diseases of companion animals. In the context of the 'One Health' approach the results related to the distribution of the zoonotic species E. aerophilus and D. immitis can be useful for medical epidemiology.
\end{abstract}

Key words: Angiostrongylus vasorum, Crenosoma vulpis, Dirofilaria immitis, Eucoleus aerophilus, red fox, Serbia

*Corresponding author; E-mail: pavlelula@yahoo.com; Phone: 00381-65-8334604; Fax: 00381-13-313208 
Cardiopulmonary parasitic diseases of Canidae species have recently become timely issues due to their emergence in European countries and their spread into previously non-endemic regions, which has been particularly well documented for diseases caused by Angiostrongylus vasorum, Crenosoma vulpis, Dirofilaria immitis and Eucoleus aerophilus (Traversa et al., 2010). Among the wild canids, the red fox is recognised as an important reservoir species for a range of parasites, including cardiopulmonary nematodes. This role of the red fox has become much more pronounced in Europe after the success of oral vaccination against rabies, which has resulted in an increase of its populations (Vos, 1995; Chautan et al., 2000) and in the tendency of extending its habitat into urban areas (Schweiger et al., 2007). In this respect, the importance of cardiopulmonary parasitic diseases of the red fox is mostly reflected in their potential risk to human and companion animal health.

The zoonotic potential of E. aerophilus as the cause of parasitic pneumonia has been confirmed in several European countries (Lalošević et al., 2008). Dirofilaria immitis is also considered a zoonotic agent, although humans are only accidental carriers of its larval forms. The disease in humans most often takes a pulmonary form and manifests itself in small, solitary peripheral pulmonary granulomas which may be very important in the differential diagnosis of pulmonary coin lesions (Echeverri et al., 1999).

With their increasing frequency reported in domestic carnivores, cardiopulmonary parasitic diseases occupy an increasingly important place in current veterinary practice (Traversa et al., 2010). The French heartworm, A. vasorum, has been shown to be very pathogenic for domestic dogs, causing cardiovascular and pulmonary disorders with potentially fatal outcome (Jolly et al., 2015; Benda et al., 2017). The fox lungworm, $C$. vulpis, can cause bronchitis with a dry, unproductive cough in dogs (Cobb and Fisher, 1992), while infection with the zoonotic lungworm $E$. aerophilus results in a similar condition in both dogs and cats (Conboy, 2009).

As the cross-host transmission between red foxes and domestic carnivores can play an important role in the epidemiology of cardiopulmonary parasitic diseases of public health and veterinary importance, the aim of the present investigations was to expand the knowledge relating to the geographical distribution of cardiopulmonary nematodes in red foxes.

\section{Materials and methods}

\section{Area and animals included in the study}

The investigations included samples from four epizootiological areas, three of which were from central Serbia and one from Vojvodina province (Fig. 1). Vojvodina province is predominantly the plains area located in the north of Ser- 
bia and demarcated by the rivers Danube and Sava from central Serbia, which consists mainly of hills and mountains. The material for examination consisted of 83 foxes which were legally hunted at different locations during a three-month period from December 2017 to February 2018. The foxes were delivered to the veterinary institutes (Veterinary Specialised Institute 'Pančevo', Veterinary Specialised Institute 'Požarevac', Veterinary Specialised Institute 'Kraljevo' and Scientific Veterinary Institute of Serbia, Belgrade) within the Programme for the Control and Eradication of Rabies in Serbia.

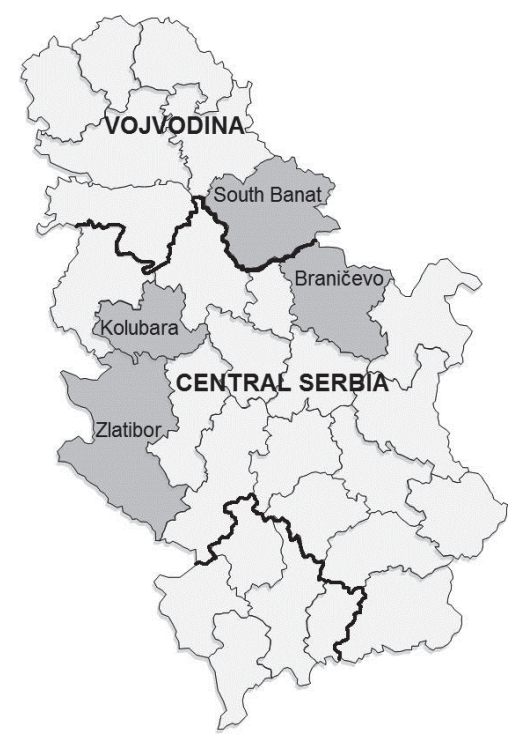

Fig. 1. The investigated epizootiological areas of Serbia

\section{Methods}

The foxes were partially necropsied and the organs of the thoracic cavity were taken out with the associated blood vessels. The heart, the pulmonary artery and its branches were cut open and the noted parasites were removed. Subsequently, the right heart ventricle, the right atrium and the pulmonary artery were washed with tap water into a kidney dish, the coagulated blood was removed and the fluid was thoroughly examined for the presence of additional parasites. The lungs were placed into a separate large kidney dish; the trachea and bronchi were cut open and the noted parasites were removed. Subsequently, the cut-open pulmonary tree was washed with tap water and the lungs were cut into small, $1 \mathrm{~cm}$ wide pieces, which were squeezed by hand under the water. The obtained fluid was sedimented for $2 \mathrm{~h}$, after which the sediment was transferred into Petri dishes and examined under a stereomicroscope (at $40 \times$ magnification). The parasites were identified on the basis of the characteristic morphological features described by Soulsby (1965) and Furtado et al. (2010). 


\section{Results}

In the territory of Serbia four species of cardiopulmonary parasitic nematodes (D. immitis, A. vasorum, C. vulpis and E. aerophilus; Fig. 2) were identified in red foxes. The presence of cardiopulmonary nematodes was detected in $69.9 \%$ of the 83 examined foxes hunted in different locations. Overall, D. immitis, A. vasorum, C. vulpis and E. aerophilus were found in $4.8 \%, 13.2 \%, 26.5 \%$ and $53.0 \%$ of the samples, respectively. Eucoleus aerophilus was prevalent in red foxes from all the four epizootiological areas examined, $C$. vulpis was detected in red foxes from three epizootiological areas, A. vasorum was found in red foxes from two epizootiological areas, while $D$. immitis was discovered in foxes from one epizootiological area located in northern Serbia (Table 1).

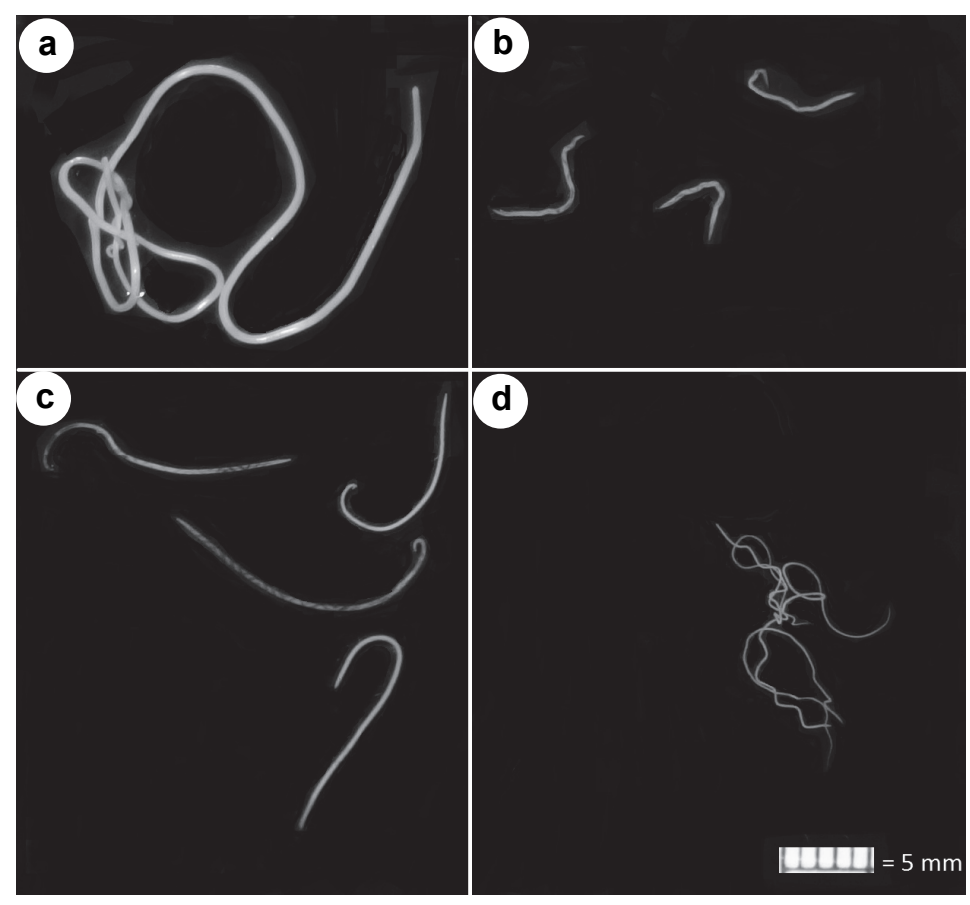

Fig. 2. Cardiopulmonary parasitic nematodes discovered in red foxes in Serbia. (a) Dirofilaria immitis, (b) Crenosoma vulpis, (c) Angiostrongylus vasorum, (d) Eucoleus aerophilus

Co-infections were detected in 19 foxes (22.9\%). Co-infection with $C$. vulpis and E. aerophilus $(15 / 18.1 \%)$ was the most frequent, followed by coinfection with $E$. aerophilus and $A$. vasorum (2/2.4\%), co-infection with $C$. vulpis and A. vasorum (1/1.2\%) and co-infection with D. immitis and E. aerophilus $(1 / 1.2 \%)$. Mixed infection with C. vulpis, A. vasorum and E. aerophilus was observed in two foxes $(2.4 \%)$. 
Table 1

Cardiopulmonary parasitic nematodes in red foxes in four epizootiological areas of Serbia

\begin{tabular}{lcccccc}
\hline $\begin{array}{l}\text { Epizootiological } \\
\text { area } \\
\text { (region) }\end{array}$ & $\begin{array}{c}\text { Number } \\
\text { of foxes } \\
\text { examined } \\
(\mathrm{n})\end{array}$ & $\begin{array}{c}\text { Positive } \\
\text { samples } \\
\mathrm{n}(\%)\end{array}$ & $\begin{array}{c}\text { D. immitis } \\
\mathrm{n}(\%)\end{array}$ & $\begin{array}{c}\text { A. vasorum } \\
\mathrm{n}(\%)\end{array}$ & $\begin{array}{c}\text { E. aerophilus } \\
\mathrm{n}(\%)\end{array}$ & $\begin{array}{c}\text { C. vulpis } \\
\mathrm{n}(\%)\end{array}$ \\
\hline $\begin{array}{l}\text { South Banat } \\
\text { (Vojvodina) }\end{array}$ & 20 & $16(80.0 \%)$ & $4(20.0 \%)$ & $9(45.0 \%)$ & $6(30.0 \%)$ & $3(15.0 \%)$ \\
$\begin{array}{l}\text { Braničevo } \\
\text { (central Serbia) }\end{array}$ & 21 & $9(42.9 \%)$ & $0(0.0 \%)$ & $0(0.0 \%)$ & $7(33.3 \%)$ & $3(14.3 \%)$ \\
$\begin{array}{l}\text { Kolubara } \\
\text { (central Serbia) }\end{array}$ & 10 & $3(30.0 \%)$ & $0(0.0 \%)$ & $0(0.0 \%)$ & $3(30.0 \%)$ & $0(0.0 \%)$ \\
$\begin{array}{l}\text { Zlatibor } \\
\text { (central Serbia) }\end{array}$ & 32 & $30(93.7 \%)$ & $0(0.0 \%)$ & $2(6.2 \%)$ & $28(87.5 \%)$ & $16(50.0 \%)$ \\
\hline \begin{tabular}{l} 
Total \\
\hline
\end{tabular} & 83 & $58(69.9 \%)$ & $4(4.8 \%)$ & $11(13.2 \%)$ & $44(53.0 \%)$ & $22(26.5 \%)$ \\
\hline
\end{tabular}

The highest intensity of infection was observed for E. aerophilus and the lowest for $D$. immitis (Table 2). The infection with $D$. immitis was unisexual in all the four infected foxes. In two foxes single male specimens were found, in one fox two female specimens were detected, while one fox harboured four female specimens. In the populations of E. aerophilus, C. vulpis and A. vasorum both sexes were present and gravid females were found in $41 \%, 19.3 \%$ and $9.6 \%$ of the red foxes examined, respectively.

All the four cardiopulmonary parasitic nematodes detected were approximately equally distributed in both sexes. The prevalence of $D$. immitis, $A$. vasorum, C. vulpis and E. aerophilus was $6 \%, 14 \%, 28 \%$ and $54 \%$ in male foxes and $3 \%, 12.1 \%, 24.2 \%$ and $51.5 \%$ in female foxes, respectively.

Table 2

Prevalence and intensity of infection with Dirofilaria immitis, Angiostrongylus vasorum, Eucoleus aerophilus and Crenosoma vulpis in red foxes in Serbia

\begin{tabular}{lcccc}
\hline & $\begin{array}{c}\text { Prevalence, } \\
\%\end{array}$ & Range & $\begin{array}{c}\text { Mean } \\
\text { intensity }\end{array}$ & $\begin{array}{c}\text { Median } \\
\text { intensity }\end{array}$ \\
\hline D. immitis & 4.8 & $1-4$ & 2 & 1.5 \\
A. vasorum & 13.2 & $1-17$ & 5.6 & 4 \\
E. aerophilus & 53.0 & $1-33$ & 8.7 & 6 \\
C. vulpis & 26.5 & $1-18$ & 4.8 & 3
\end{tabular}




\section{Discussion}

The investigations confirmed that cardiopulmonary nematodes are widespread in red foxes in Serbia. The most widespread is the zoonotic species $E$. aerophilus, found in all the four epizootiological areas examined. The highest prevalence of infection $(87.5 \%, 28 / 32)$ was determined in the Zlatibor epizootiological area, which is a mountainous region of central Serbia. In different European countries, the prevalence of infection ranges from $0.3 \%$ in central Poland (Borecka et al., 2009) to $88 \%$ in Norway (Davidson et al., 2006). The present findings, coupled with previous studies reporting a prevalence of E. aerophilus within a range of 30-84\% for different regions of Serbia (Lalošević et al., 2013; Ilić et al., 2016; Bjelić Čabrilo et al., 2018) imply that there is a potential risk of infection for susceptible animals and humans across the whole country. Pulmonary capillariosis in humans is a very rare disease, and there are only a few cases, including just one from Serbia (Lalošević et al., 2008), reported in the international literature. Despite the wide distribution of E. aerophilus in Serbia, there have been no data related to eucoleosis in dogs and cats. In neighbouring Romania, for instance, the prevalence of eucoleosis in household cats has been estimated at 3.1\% (Mircean et al., 2010).

The relatively high prevalence of $D$. immitis in red foxes in the South Banat epizootiological area, northern Serbia, coincides with an enzootic area of canine dirofilariosis around the rivers Danube and Tamiš. The first case of heartworm disease in a dog in South Banat was reported in 1995 in the City of Pančevo (Blitva-Mihajlović et al., 1995), and in the subsequent two decades this area proved to be enzootic for canine dirofilariosis caused by $D$. immitis (Tasić et al., 2012; Gavrilović et al., 2015).

Although the reproduction of $D$. immitis in the red fox has been confirmed (Magi et al., 2008), the role of this host species in the epizootiology of the disease is still obscure. The maximum number of adult parasites (four) found in red foxes in the present study is lower as compared with dogs in the investigated area (Gavrilović, unpublished data), which may indicate that the red fox is a less susceptible host species. This opinion is supported by the fact that $D$. immitis was not found in red foxes in central Serbia, although the disease is prevalent in dogs (Tasić et al., 2012). A high prevalence of infection suggests the possibility that D. immitis is also maintained, in South Banat, in a sylvatic cycle in which the role of definitive host has been taken by the red fox. However, the reproduction of D. immitis, which would support such an opinion, could not be demonstrated in the animals examined. In the neighbouring countries, dirofilariosis has been reported in red foxes with a prevalence of $3.7 \%$ in Hungary (Tolnai et al., 2014) and $25.2 \%$ in Bulgaria (Panayotova-Pencheva et al., 2016).

In the present investigations $A$. vasorum was found for the first time in the territory of central Serbia, Zlatibor epizootiological area. The infected foxes orig- 
inated from villages adjacent to the municipality of Gornji Milanovac. Similarly, all the infected foxes from South Banat (Vojvodina) originated from the area of Pančevo municipality, confirming that the disease exists in Serbia in enzootic foci. This is the most probable reason why, unlike the present investigations, Bjelić Cabrilo et al. (2018) found A. vasorum in only three individual foxes (1.8\%) from Vojvodina, each of which carried a single worm. In addition to red foxes, the disease has been described in a dog (Simin et al., 2014) and in a golden jackal (Gavrilović et al., 2017) in Vojvodina province.

The trend towards a higher incidence of angiostrongylosis observed in some European countries indicates that $A$. vasorum is actually emerging in Europe. A high prevalence of infection (17.9\%) has been recorded in Hungary, the country bordering Serbia to the north (Tolnai et al., 2015). In Croatia, bordering Serbia to the west, the prevalence of infection in red foxes is less than 5\% (Rajković-Janje et al., 2002) and, similarly, in West Romania bordering Serbia to the east the prevalence was estimated at 4.2\% (Deak et al., 2017).

Although angiostrongylosis may be fatal in domestic dogs (Jolly et al., 2015; Benda et al., 2017), the disease is still neglected among practitioners in Serbia. Based on the present investigations dogs from two municipalities, Pančevo and Gornji Milanovac, should be considered to be at a high risk of angiostrongylosis. Currently, canine angiostrongylosis is endemic in many areas of Europe (Elsheikha et al., 2014), and in neighbouring Hungary, for instance, Schnyder et al. (2015) found 1.36\% Angiostrongylus antibody- and antigenpositivity in dogs.

The fox lungworm, C. vulpis, was found in three epizootiological areas and for the first time in the territory of central Serbia. Previous investigations reported the occurrence of this agent with a prevalence of $13.1 \%$ (Simin et al., 2012) and 16.6\% (Bjelić Čabrilo et al., 2018) in Vojvodina province. The prevalence of infection in Europe ranges from 2 to 58\% (Davidson et al., 2006; Morgan et al., 2008), and in some regions such as the Pyrenees in north-eastern Spain, it is the most frequent cardiopulmonary nematode $(44.8 \%)$ (GarridoCastañé et al., 2015). Of the neighbouring countries, a prevalence of $24 \%$ was reported in red foxes in Hungary (Sréter et al., 2003).

Due to the unspecific clinical signs and difficulties in making a diagnosis, crenosomosis can be an important health issue for veterinary medicine (Cobb and Fisher, 1992; Rinaldi et al., 2007). Individual cases of the disease were recorded in domestic dogs (Cobb and Fisher, 1992; Reilly et al., 2000) and the prevalence of infection was estimated in some countries such as Germany $(6.0 \%$; Barutzki and Schaper, 2009), and the Czech Republic (2.0\%; Hajnalová et al., 2018).

In conclusion, cardiopulmonary nematodes $D$. immitis, $A$. vasorum, $C$. vulpis and E. aerophilus are widespread in red foxes in Serbia. Crenosoma vulpis and E. aerophilus are detected in foxes in both the plains and mountainous areas across the country. Dirofilaria immitis is distributed in red foxes near alluvial 
rivers. Angiostrongylosis has been demonstrated to exist in two enzootic foci with a high percentage of infected foxes in the plains area of northern Serbia. To the best of our knowledge, C. vulpis and A. vasorum were discovered for the first time in red foxes in central Serbia in the present study.

The results provide strong evidence for veterinarians to take into consideration the parasitic nematodes discovered in red foxes in the differential diagnosis of diseases of companion animals. In the context of the 'One Health' approach the results related to the distribution of the zoonotic species E. aerophilus and $D$. immitis can be useful for medical epidemiology.

\section{References}

Barutzki, D. and Schaper, R. (2009): Natural infections of Angiostrongylus vasorum and Crenosoma vulpis in dogs in Germany (2007-2009). Parasitol. Res. 105, 39-48.

Benda, T., Csivincsik, A., Nemes, C., Turbok, J., Zsolnai, A., Simonyai, E., Majoros, G. and Nagy, G. (2017): Lethal Angiostrongylus vasorum infection in a Hungarian dog. Acta Parasitol. 62, 221-224.

Bjelić Čabrilo, O., Simin, V., Miljević, M., Čabrilo, B., Mijatović, D. and Lalošević, D. (2018): Respiratory and cardiopulmonary nematode species of foxes and jackals in Serbia. Helminthologia 55, 213-221.

Blitva-Mihajlović, G., Ralić, M. and Miletić, B. (1995): Heartworm disease. In: Small Animals Life and Health Symposium [in Serbian]. 23-26 May, 1995, Belgrade, Serbia. p. 123.

Borecka, A., Gawor, J., Malczewska, M. and Malczewski, A. (2009): Prevalence of zoonotic helminth parasites of the small intestine in red foxes from central Poland. Med. Weter. 65, 33-35.

Chautan, M., Pontier, D. and Artois, M. (2000): Role of rabies in recent demographic changes in red fox populations in Europe. Mammalia 64, 391-410.

Cobb, M. A. and Fisher, M. A. (1992): Crenosoma vulpis infection in a dog. Vet. Rec. 130, 452.

Conboy, G. (2009): Helminth parasites of the canine and feline respiratory tract. Vet. Clin. North Am. Small Anim. Pract. 39, 1109-1126.

Davidson, R. K., Gjerde, B., Vikøren, T., Lillehaug, A. and Handeland, K. (2006): Prevalence of Trichinella larvae and extra-intestinal nematodes in Norwegian red foxes (Vulpes vulpes). Vet. Parasitol. 136, 307-316.

Deak, G., Gherman, C. M., Ionică, A. M., Vezendan, A. D., D’Amico, G., Matei, I. A., Daskalaki, A. A., Marian, I., Damian, A., Cozma, V. and Mihalca, A. D. (2017): Angiostrongylus vasorum in Romania: an extensive survey in red foxes, Vulpes vulpes. Parasit. Vectors 10, 330.

Echeverri, A., Long, R. F., Check, W. and Burnett, C. M. (1999): Pulmonary dirofilariasis. Ann. Thorac. Surg. 67, 201-202.

Elsheikha, H. M., Holmes, S. A., Wright, I., Morgan, E. R. and Lacher, D. W. (2014): Recent advances in the epidemiology, clinical and diagnostic features, and control of canine cardiopulmonary angiostrongylosis. Vet. Res. 45, 92.

Furtado, A. P., Melo, F. T., Giese, E. G. and dos Santos, J. N. (2010): Morphological redescription of Dirofilaria immitis. J. Parasitol. 96, 499-504.

Garrido-Castañé, I., Ortuño, A., Marco, I. and Castellà, J. (2015): Cardiopulmonary helminths in foxes from the Pyrenees. Acta Parasitol. 60, 712-715.

Gavrilović, P., Blitva-Robertson, G., Ozvegy, J., Kiskaroly, F. and Becskei, Z. (2015): Case report of dirofilariasis in grey wolf in Serbia. Acta Parasitol. 60, 175-178. 
Gavrilović, P., Marinković, D., Todorović, I. and Gavrilović, A. (2017): First report of pneumonia caused by Angiostrongylus vasorum in a golden jackal. Acta Parasitol. 62, 880-884.

Hajnalová, M., Svobodová, V., Schnyder, M., Schaper, R. and Svoboda, M. (2018): Faecal detection of the lungworms Crenosoma vulpis and Angiostrongylus vasorum and serological detection of A. vasorum in dogs from the Czech Republic. Acta Vet. Brno 86, 393-398.

Ilić, T., Becskei, Z., Tasić, A., Stepanović, P., Radisavljević, K., Đurić, B. and Dimitrijević, S. (2016): Red foxes (Vulpes vulpes) as reservoirs of respiratory capillariosis in Serbia. J. Vet. Res. 60, 153-157.

Jolly, S., Poncelet, L., Lempereur, L., Caron, Y., Bayrou, C., Cassart, D., Grimm, F. and Losson, B. (2015): First report of a fatal autochthonous canine Angiostrongylus vasorum infection in Belgium. Parasitol. Int. 64, 97-99.

Lalošević, D., Lalošević, V., Klem, I., Stanojev-Jovanović, D. and Pozio, E. (2008): Pulmonary capillariasis miming bronchial carcinoma. Am. J. Trop. Med. Hyg. 78, 14-16.

Lalošević, V., Lalošević, D., Čapo, I., Simin, V., Galfi, A. and Traversa, D. (2013): High infection rate of zoonotic Eucoleus aerophilus infection in foxes from Serbia. Parasite 20, 3.

Magi, M., Calderini, P., Gabrielli, S., Dell'Omodarme, M., Macchioni, F., Prati, M. C. and Cancrini, G. (2008): Vulpes vulpes: a possible wild reservoir for zoonotic filariae. Vector Borne Zoonotic Dis. 8, 249-252.

Mircean, V., Titilincu, A. and Vasile, C. (2010): Prevalence of endoparasites in household cat (Felis catus) populations from Transylvania (Romania) and association with risk factors. Vet. Parasitol. 171, 163-166.

Morgan, E. R., Tomlinson, A., Hunter, S., Nichols, T., Roberts, E., Fox, M. T. and Taylor, M. A. (2008): Angiostrongylus vasorum and Eucoleus aerophilus in foxes (Vulpes vulpes) in Great Britain. Vet. Parasitol. 154, 48-57.

Panayotova-Pencheva, M. S., Mirchev, R. L. and Trifinova, A. P. (2016): Dirofilaria immitis infection in carnivores from Bulgaria: 2012-2013 update. Bulg. J. Vet. Med. 19, 153-162.

Rajković-Janje, R., Marinculić, A., Bosnić, S., Benić, M., Vinković, B. and Mihaljević, Ž. (2002): Prevalence and seasonal distribution of helminth parasites in red foxes (Vulpes vulpes) from Zagreb County (Croatia). Z. Jagdwiss. 48, 151-160.

Reilly, G. A. C., McGarry, J. W., Martin, M. and Belford, C. (2000): Crenosoma vulpis, the fox lungworm, in a dog in Ireland. Vet. Rec. 146, 764-765.

Rinaldi, L., Calabria, G., Carbone, S., Carrella, A. and Cringoli, G. (2007): Crenosoma vulpis in dog: first case report in Italy and use of the FLOTAC technique for copromicroscopic diagnosis. Parasitol. Res. 101, 1681-1684.

Schnyder, M., Schaper, R., Lukács, Z., Hornok, S. and Farkas, R. (2015): Combined serological detection of circulating Angiostrongylus vasorum antigen and parasite-specific antibodies in dogs from Hungary. Parasitol. Res. 114, 145-154.

Schweiger, A., Ammann, R. W., Candinas, D., Clavien, P. A., Eckert, J., Gottstein, B., Halkic, N., Muellhaupt, B., Prinz, B. M., Reichen, J., Tarr, P. E., Torgerson, P. R. and Deplazes, P. (2007): Human alveolar echinococcosis after fox population increase, Switzerland. Emerg. Infect. Dis. 13, 878-882.

Simin, S., Kosić, L. S., Kuruca, L., Pavlović, I., Savović, M. and Lalošević, V. (2014): Moving the boundaries to the South-East: first record of autochthonous Angiostrongylus vasorum infection in a dog in Vojvodina province, northern Serbia. Parasit. Vectors 7, 396-402.

Simin, V., Lalošević, V., Galfi, A., Božić, M., Obradović, N. and Lalošević, D. (2012): Crenosoma vulpis (Dujardin 1844) (Nematoda, Crenosomatidae) in foxes in Vojvodina Province, Serbia. Biologia Serbica 34, 71-74.

Soulsby, E. J. L. (1965): Textbook of Veterinary Clinical Parasitology. Volume 1. Helminths. Blackwell Scientific Publications, Oxford. pp. 66-83.

Sréter, T., Széll, Z., Marucci, G., Pozio, E. and Varga, I. (2003): Extraintestinal nematode infections of red foxes (Vulpes vulpes) in Hungary. Vet. Parasitol. 115, 329-334. 
Tasić, A., Tasić-Otašević, S., Gabrielli, S., Miladinović-Tasić, N., Ignjatović, A., Đorđević, J., Dimitrijević, S. and Cancrini, G. (2012): Canine Dirofilaria infections in two uninvestigated areas of Serbia: epidemiological and genetic aspects. Vector Borne Zoonotic Dis. 12, 1031-1035.

Tolnai, Z., Széll, Z. and Sréter, T. (2015): Environmental determinants of the spatial distribution of Angiostrongylus vasorum, Crenosoma vulpis and Eucoleus aerophilus in Hungary. Vet. Parasitol. 207, 355-358.

Tolnai, Z., Széll, Z., Sproch, Á., Szeredi, L. and Sréter, T. (2014): Dirofilaria immitis: an emerging parasite in dogs, red foxes and golden jackals in Hungary. Vet. Parasitol. 203, 339-342.

Traversa, D., Di Cesare, A. and Conboy, G. (2010): Canine and feline cardiopulmonary parasitic nematodes in Europe: emerging and underestimated. Parasit. Vectors 3, 62.

Vos, A. C. (1995): Population dynamics of the red fox (Vulpes vulpes) after the disappearance of rabies in county Garmisch-Partenkirchen, Germany, 1987-1992. Ann. Zool. Fennici 32, 93-97. 